The Journal of Engineering and Exact Sciences - jCEC, Vol. 06 N. 02 (2020)

journal homepage: https://periodicos.ufv.br/ojs/jcec

doi: 10.18540/jcecvl6iss2pp0129-0138

OPEN ACCESS - ISSN: 2527-1075

\title{
STOCHASTIC MODELING OF LIVING/CONTROLLED COPOLYMERIZATIONS IN TUBULAR REACTORS WITH LATERAL FEED
}

\begin{abstract}
M. D. Carvalho ${ }^{1}$, T. S. M. Lemos ${ }^{2}$, J. D. A. Bellido ${ }^{3}$ and A. M. O. Siqueira ${ }^{4}$
${ }^{1}$ Federal University of Viçosa, Chemical Engineering Program, Viçosa, MG, Brazil, E-mail: matheus.d.carvalho@ufv.br, ORCID: https://orcid.org/0000-0002-2531-4466

${ }^{2}$ Federal University of Rio de Janeiro, Chemical Engineering Program/COPPE, University City, Technology Center, Rio de Janeiro, RJ, Brazil, E-mail: tsmlemos@hotmail.com, ORCID: https://orcid.org/0000-0002-0327-7545

${ }^{3}$ Federal University of São João Del-rei, Campus Alto Paraopeba (CAP), Ouro Branco, MG, Brazil, E-mail: jorgeb@ufsj.edu.br, ORCID: https://orcid.org/0000-0003-0186-5586

${ }^{4}$ Federal University of Viçosa, Chemical Engineering Program, Viçosa, MG, Brazil, E-mail: antonio.siqueira@ufv.br, ORCID: https://orcid.org/0000-0001-9334-0394

${ }^{*}$ Corresponding author. Federal University of Viçosa, Department of Chemical Engineering, Viçosa, Minas Gerais, Brazil, Phone: +55 31 3612-6657, e-mail address: matheus.d.carvalho@ufv.br (M.D. Carvalho).
\end{abstract}

\begin{tabular}{l} 
A R T I C L E I N F O \\
\hline Article history: \\
Received 2020-02-03 \\
Accepted 2020-06-17 \\
Available online 2020-06-17 \\
keywords \\
Polymerization \\
Monte Carlo \\
Microstructure \\
Stochastic
\end{tabular}

\begin{abstract}
A B S T R A C T
It is known the controlled microstructure polymers production increase in continuous reactors due to all industrial advantages that this type of operation presents. In this paper, the synthesis via Nitroxide-Mediated Polymerization (NMP) of copolymers based on styrene and methyl methacrylate accomplished in a tubular reactor with lateral feed is modeled by Kinect Monte Carlo (kMC). This reactional configuration aims the copolymers production with originals microstructure and applications. There were obtained all the microstructural properties distributions of the synthesized material at interest and the conversion values, Polydispersity Index (PDI) and chains average molar mass are compared to experimental data. The conversion presented minimum and maximum deviation in the module of 0.61 and $-21.85 \%$, respectively. For the PDI and the molar mass, there were obtained minimum and maximum errors of $0.72 \%, 1.50 \%,-23.10 \%$ and $1.77 \%$, respectively. It was verified that the formed product differed from the expected one in experiments. There were found copolymers of polystyrene-b-poly(methyl styrene-rand-methacrylate), not being found any region that presented composition gradient through the chains, differently than it had been foreseen in the experimental synthesis, results that show the relevance of a stochastic simulation in the process to make decisions in the context of polymer reaction engineering.
\end{abstract}




\section{INTRODUCTION}

The knowledge of the polymers microstructure properties is fundamental for the technological applications development of these materials, therefore, it is derived all its macroscopic properties, which are determinants on its applicabilities (Odian, 2004). In this context, the Controlled Radical Polymerization (CRP) techniques, assume primordial importance, because allows the reaction medium control, is possible to project both the size of the chain, diminishing the microstructure heterogeneity, as well as chains architecture, turning possible the production of the copolymers of graft, block, and tapered (Trepka,1992; Beers et al., 1998; Hutchinson and Penlidis, 2007). Each of these configurations results in materials with inherent characteristics.

Small variations in the polymer microstructure might conduct to great performance variations. For example, the difference between the PVC and the CPVC, materials used predominantly in hydraulic and electrical installations, is established by the chloride addiction during the PVC polymerization, leading the CPVC formation, being the latter the most resistance to higher temperatures, what makes it indicated for hot water installations. Additionally, there is the chain size, which is a proportional magnitude to the polymer viscosity, being the differential between the lubricating oils and greases, which also differ as to the temperature range for the application (Rubinstein and Colby, 2003).

Recently, it has been increased the interest to use the continuous reactor for the conduction of controlled polymerization reactions, due to the industrial importance these continuous processes have (Hustad and Kuhlman, 2007; Araujo and Pinto, 2013; Morsbach et al., 2016). It is possible to cite experimental and theoric studies about the polymerization in mixing tanks and tubular reactors (AlHarthi et al., 2009; Wang and Broadbelt, 2009).

The continuous reactors have Residence Time Distributions (RTD), which reflects in an increase of the heterogeneity of the created products by CRP, however, these materials of greater microstructure dispersion might present, just as the traditional controlled materials, produced in batch, interesting behaviors, as self-assembly (Bendejacq et al., 2002; Hillmyer, 2007).

The use of a tubular reactor might results in various advantages, as the low demand energy for the heating and the mixture, the high rate area/volume, which results in a greater thermal exchange rate, becoming easy the temperature control (Wang and Broadbelt, 2009). Additionally, the residence time is easily manipulated by the feeding flows. The possibility to work with lateral feeding might also conduce copolymers manufacturing with uniques characteristics (Wang and Broadbelt, 2009).

Araújo and Pinto (2013) performed an experimental study in which they synthesized copolymers based on styrene and methyl methacrylate (STY-MMA) via Nitroxide-Mediated Polymerization (NMP). The authors used a tubular reactor equipped with a lateral feed and they obtained the conversion of 20 to $70 \%$, chains average molar mass between 30,000 and 60,000 g/mol and Polydispersity Index (PDI) of 1.3 and 1.6. The reactor primary entrance is fed with styrene and in the lateral entrance, MMA is added.
The authors highlighted the possibility of the configuration to conduct the production of the copolymer with bimodal Chain Length Distributions (CLD), blends in situ, and they ventured the polystyrene-b-poly(styrene-grad-MMA) production.

The tapered copolymers are materials that have special applications, exactly to combine the properties of two or more monomers in a customized form. During its production, the aim is to obtain chains with tails that have the predominance of a monomeric component to other, occurring the inversion on the contrary side (Araujo and Pinto, 2013). These materials are usually utilized in packaging production with good properties to the resistance to environmental stress (Van Steenberge et al., 2012; Araujo and Pinto, 2013). Within the scope of these materials of a living/controlled microstructure, the stochastic modeling techniques of the polymerization process turn particularly interesting when compared to the deterministic traditional techniques, of writing and resolution of mass balance equations for the system components. These balances can be hard to resolve, given the greater species quantity present in the polymerization systems. The stochastic techniques allow, in a simple form, to simulate the polymerization process to obtain all the microstructure information of the generated chains, a knowledge that enables to analyze the efficiency of the given application and, consequently, its viability (Al-Harthi et al., 2009; Wang and Broadbelt, 2009; Van Steenberge et al., 2012; Lemos, Melo and Pinto, 2015).

There are various stochastic methodologies of polymeric microstructures sampling, as presented in the famous papers of Hidetaka Tobita, through the microstructures properties distributions (Tobita, 1993), e others based on the kinetic Monte Carlo (kMC) simulations, that describes the polymerization kinetic (Wang and Broadbelt, 2009; Van Steenberge et al., 2012; Lemos, Melo and Pinto, 2015; Brandão et al., 2015).

The present study has the aim to simulate through $\mathrm{kMC}$, the situations developed experimentally by the Araújo and Pinto (2013) study. For comparative effect, there are obtained monomeric conversion data, PDI and chains molar mass. Additionally, using the stochastic modeling potential, there are found the molar function of the size of the chain, the blocks size, and the product microstructure distribution, and it is performed a critic comparison between the obtained experimentally (Araujo and Pinto, 2013) and via simulation results. With the adopted approach, the present text searches to exhibit stochastic modeling as a reliable methodology to extract polymerization results, to auxiliary the experimental studies and to contribute as a tool for the production of special materials with projected properties.

In Section 2, it is presented the details of the experimental analysis practiced by Araújo and Pinto (2013), as well as the particularities of the stochastic algorithm used to simulate the polymerizations. It was utilized the Lemos et al. (2015) developments to the stochastic simulation for continuous systems. It is also presented, the kinetic model used to describe the polymerizations. In Section 3, it is exhibited the simulation results, which consists of the complete microstructure of the created polymer. From the microstructure, it is calculated, for comparative effects, the same properties described by Araújo and Pinto (2013), the conversion, average molar mass, and PDI. It is performed discussions about the results. 


\section{METHODOLOGY}

\subsection{Polymerization Experiments from Araújo and Pinto} (2013)

The polymerization is carried out isothermally, at 135 ${ }^{\circ} \mathrm{C}$, in a tubular reactor. It was used two different initiators, the benzoyl peroxide (BPO) and the tert-butylperoxy 2ethylhexyl carbonate (TBEC), and the authors credited to this initiator mixture, the achievement of elevating conversions. It is a mediated CRP by nitroxide (NMP), which it was used TEMPO (2,2,6,6-tetramethyl-1piperidinyloxy) and capture agent. The rate of the nitroxide and initiator concentration was between 1.1 and 1.5.

The reactor has two feed streams, one primary where it inserts the styrene, and other lateral, when existent, it feeds with MMA. The authors used two configurations, one for the polystyrene formation, that does not use the lateral feed, named Polymerization 1. Whereas, the Polymerization 2 aims the formation of Styrene/MMA tapered block copolymers. The concentration of each reagent used in the Araújo and Pinto (2013) paper that compound the primary and lateral feeding currents are exhibited in Table 1.

Table 1 - Concentrations of reagents involved in each reaction carried out by Araújo \& Pinto (2013).

\begin{tabular}{lccc} 
& Reagent & $\begin{array}{c}\text { Polymerization } \\
\mathbf{1}(\mathbf{m o l} / \mathbf{L})\end{array}$ & $\begin{array}{c}\text { Polymerization } \\
\mathbf{2}(\mathbf{m o l} / \mathbf{L})\end{array}$ \\
Primary & BPO & 5.18 & 4.32 \\
Feed & TBEC & 0.0026 & 4.88 \\
& TEMPO & 0.0040 & 0.0021 \\
Lateral & Methyl & & 0.0032 \\
Feed & methacry & - & \\
& late & & 9.99 \\
& TEMPO & - & 0.0034 \\
\hline
\end{tabular}

These two experimental analyses were performed in two stationary configurations with different residence times, to totalize four differents polymerizations. Table 2 exhibits the average residence times involved in each system. The symbology $\tau_{\mathrm{h}}$ and $\tau_{\mathrm{c}}$ represent, respectively, the average residence times in the homopolymerization and copolymerization stages accomplished by the authors.

Table 2: Average residence times of experiments by Araújo and Pinto (2013).

\begin{tabular}{ccccc}
\hline & & Polymerization 1 (s) & Polymerization 2 (s) \\
State 1 & $\tau_{\mathrm{h}}$ & 4920 & 4920 \\
& $\tau_{\mathrm{c}}$ & - & 4380 \\
& $\tau_{\text {overall }}$ & 4920 & 9300 \\
& $\tau_{\mathrm{h}}$ & 19680 & 19680 \\
State 2 & $\tau_{\mathrm{c}}$ & - & 13140 \\
& $\tau_{\text {overall }}$ & 19680 & 32820 \\
\hline
\end{tabular}

\subsection{The Kinect Monte Carlo Algorithm Applied To} Tubular Reactors

The simulation method is based on the kinect Monte Carlo or the Gillespie algorithm, which is a method the simulated the temporal evolution and the kinect process in batch (Gillespie, 1976). The method is based on the iterative response of two questions, which are: when the next reaction is going to occur and which, among the possible reactions, will be the reaction. To answer these questions, it is defined as the probabilities for the possible events in the system and it is used random numbers to perform sampling.

The propensity function quantifies the probability of a given reaction occurs in a determined time interval, being this function of the reagent molecular number in the reaction volume and deterministic kinetic constant of the reaction. The representation of this function is given by $a_{\mu}(X)$ (AlHarthi et al., 2009) being also written as a product of two others functions, as shown in Equation 1:

$a_{\mu}(X)=h_{\mu}(X) c_{\mu}$

Which $h_{\mu}(X)$ is the combination factor, representing all the possible combinations between the molecule's reagents of $\mu$ reaction, and $c_{\mu}$ the stochastic constant, related to the deterministic kinect constant $k$. The structure of these two terms variates according to the type of reaction, as shown in Table 3, where it is exhibited expressions for each term, in order the $\mathrm{X}, \mathrm{Y}, \mathrm{Z}$, and $\mathrm{W}$ represent the molecular number of each reagent, $V$ is the medium total volume and $N_{A}$ is the Avogadro constant.

Table 3: Combination factor structure and stochastic constant for common reaction types (Lemos, Melo and Pinto, 2015).

\begin{tabular}{ccc} 
Reaction type & $\begin{array}{c}\text { Combination } \\
\text { factor }\end{array}$ & $\begin{array}{c}\text { Stochastic } \\
\text { constant }\end{array}$ \\
\hline $\mathrm{X} \rightarrow$ products & $h(\mathrm{X})=\mathrm{X}$ & $c=k$ \\
$\mathrm{Y}+\mathrm{Z} \rightarrow$ products & $h(\mathrm{Y}, \mathrm{Z})=\mathrm{Y} \cdot \mathrm{Z}$ & $c=\frac{k}{V N_{A}}$ \\
$2 \mathrm{~W} \rightarrow$ products & $h(\mathrm{~W})=\frac{\mathrm{W}(\mathrm{W}-1)}{2}$ & $c=\frac{2 k}{V N_{A}}$ \\
\hline
\end{tabular}

The time sampling of a reactional event is accomplished by Equation 2 (Lemos, Melo and Pinto, 2015), where $\Delta$ represents the elapsed time between the two chemical reactions. The $a_{0}$ symbol represents the total propensity function, which is obtained by the summation of the propensity function of $M$ possible chemical reaction, while rand $_{1}$ is a random number showed of a uniform distribution in the $(0,1)$ interval:

$\Delta=\frac{1}{\sum_{r=1}^{M} a_{r}} \ln \left(\frac{1}{\text { rand }_{1}}\right)=\frac{1}{a_{0}} \ln \left(\frac{1}{\text { rand }_{1}}\right)$.

The event (reaction) sampling is performed by the smaller inner number $\mu$ that compiles the Equation (3), where rand $_{2}$ is a random number selected through a uniform distribution in the $(0,1)$ interval:

$\sum_{r=1}^{\mu} a_{r} \geq \operatorname{rand}_{2} a_{0}$.

After each iteration, it must be actualized the time, the number of molecules and the propensity functions of the system, obtaining the temporal evolution of the kinetic 
system. The iterations are accomplished until the previously established residence time is achieved.

To simulate the tubular reactor configuration used in the Araújo and Pinto(2013) polymerization, it was used as a procedure presented by Lemos et al. (2015) to extend the $\mathrm{kMC}$, defined originally to batch process, to a continuous process. This procedure considers that it does not occur micromixing effects, which is an acceptable hypothesis for high viscosity system, as the free radical polymerizations in bulk, and heterogeneous systems, as the suspension and emulsion polymerizations.

Completely segregated systems are simulated through the reactor separation in various isolated compartments, to make the diffusion null between them Each compartment is treated as a batch reactor, therefore each one has a residence time. The residence times are determined based on the Residence Time Distribution Function (RTD), with easy obtainment experimentally.

A possible function to represent the RTD of the nonideals tubular reactor is the log-normal, presented in the Equation 4 (Lemos, Melo and Pinto, 2015).

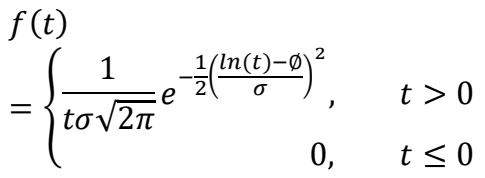

Where the $\varnothing$ and $\sigma$ parameters are dependents of the average residence time $(\tau)$ and the Distribution Function variance $(\theta)$, according to Equations 5 and 6 .

$\varnothing=\ln \left(\frac{\tau^{2}}{\sqrt{\theta+\tau^{2}}}\right)$

$$
\sigma=\sqrt{\ln \left(1+\frac{\theta}{\tau^{2}}\right)}
$$

Given an initial sample volume $V$, to be fractionated in $n$ equal parts, the volume of each simulated fraction is $V_{\text {sim }}=V / n$. Each fraction is treated by $\mathrm{kMC}$ as an independent batch, being the simulation time founded by RTD discretization, adopting an average residence time according to Equation 7. For details of this procedure, one must consult Lemos et al. (2015).

$$
t_{s i m, i}=\frac{\int_{t_{i, \min }}^{t_{i, \max }} t f(t) d t}{\int_{t_{i, \min }}^{t_{i, \max }} f(t) d t}=\mathrm{n} \int_{t_{i, \min }}^{t_{i, \max }} t f(t) d t
$$

\subsection{The Kinetic Model and Parametrization}

The kMC requires a kinetic model that specifies the chemical reaction and its deterministic propensities. It was described two kinetic mechanisms, one for each obtained experimental analysis, through literature data in the area, the kinetic constants. The mechanism for the Polymerization 1 (homopolymerization of styrene) is exhibited in Table 4, and the mechanism for the Polymerization 2 (copolymerization of styrene-co-MMA) is presented in Table 5.

Among the used symbols, I1, I2, $\mathrm{M}_{1}, \mathrm{M}_{2}, \mathrm{R} 1, \mathrm{R} 2$, and $\mathrm{X}$, represent, respectively, the BPO, TBEC, styrene, methyl methacrylate, BPO decomposition radical, TBEC decomposition radical and TEMPO molecules. The symbols $\mathrm{P}_{\mathrm{i}, \mathrm{j}}, \mathrm{Q}_{\mathrm{i}, \mathrm{j}}, \mathrm{Z}_{\mathrm{i}, \mathrm{j}}, \mathrm{W}_{\mathrm{i}, \mathrm{j}}$ and $\mathrm{L}_{\mathrm{i}, \mathrm{j}}$ represent the chains, being this distinct symbology according to the last unit that component it and its activity state. More specifically, $\mathrm{P}_{\mathrm{i}, \mathrm{j}}$ represents the active chains with $\mathrm{i}$ styrene repeating units and $\mathrm{j}$ methyl methacrylate repeating units, being the last component coming from styrene monomer. $\mathrm{Q}_{\mathrm{i}, \mathrm{j}}$ has a similar meaning, however, the latter repetition unit added comes from MMA. $\mathrm{Z}_{\mathrm{i}, \mathrm{j}}$ is about dormant structures that have MMA as the final

\begin{tabular}{|c|c|c|c|}
\hline Step & Mechanism & Expressions for kinetic constants & References \\
\hline \multirow{4}{*}{ Initiattion } & $\mathrm{I} 1 \stackrel{\mathrm{k}_{1}}{\longrightarrow} 2 \mathrm{R} 1$ & $\mathrm{k}_{1}=8.775 \times 10^{-3} \mathrm{~s}^{-1}$ & $\begin{array}{l}\text { Zhang and Ray } \\
\text { (2002) }\end{array}$ \\
\hline & $\mathrm{I} 2 \stackrel{\mathrm{k}_{2}}{\longrightarrow} 2 \mathrm{R} 2$ & $\mathrm{k}_{3}=4.340 \times 10^{-2} \mathrm{~L} \mathrm{~mol}^{-1} \mathrm{~s}^{-1}$ & $\begin{array}{l}\text { Dhib, Gao and } \\
\text { Penlidis (2000) }\end{array}$ \\
\hline & $\mathrm{R} 1+\mathrm{M} \stackrel{\mathrm{k}_{3}}{\longrightarrow} \mathrm{P}_{1}$ & $\mathrm{k}_{3}=4.340 \times 10^{-2} \mathrm{~L} \mathrm{~mol}^{-1} \mathrm{~s}^{-1}$ & $\begin{array}{c}\text { Zhang and Ray } \\
\text { (2002) }\end{array}$ \\
\hline & $\mathrm{R} 2+\mathrm{M} \stackrel{\mathrm{k}_{4}}{\longrightarrow} \mathrm{P}_{1}$ & $\mathrm{k}_{4}=1.367 \times 10^{-3} \mathrm{~L} \mathrm{~mol}^{-1} \mathrm{~s}^{-1}$ & $\begin{array}{l}\text { Dhib, Gao and } \\
\text { Penlidis (2000) }\end{array}$ \\
\hline Propagation & $\mathrm{P}_{\mathrm{i}}+\mathrm{M} \stackrel{\mathrm{k}_{5}}{\longrightarrow} \mathrm{P}_{\mathrm{i}+1}$ & $\mathrm{k}_{5}=4.340 \times 10^{-2} \mathrm{~L} \mathrm{~mol}^{-1} \mathrm{~s}^{-1}$ & $\begin{array}{c}\text { Zhang and Ray } \\
\text { (2002) }\end{array}$ \\
\hline \multirow[b]{2}{*}{ Equilibrium with nitroxide } & $\mathrm{P}_{\mathrm{i}}+\mathrm{X} \stackrel{\mathrm{k}_{6}}{\longrightarrow} \mathrm{Z}_{\mathrm{i}}$ & $\mathrm{k}_{6}=3.799 \times 10^{1} \mathrm{~L} \mathrm{~mol}^{-1} \mathrm{~s}^{-1}$ & $\begin{array}{c}\text { Zhang and Ray } \\
\text { (2002) }\end{array}$ \\
\hline & $\mathrm{P}_{\mathrm{i}}+\mathrm{X} \stackrel{\mathrm{k}_{7}}{\longleftarrow} \mathrm{Z}_{\mathrm{i}}$ & $\mathrm{k}_{7}=2.500 \times 10^{-3} \mathrm{~s}^{-1}$ & $\begin{array}{l}\text { Zhang and Ray } \\
\text { (2002) }\end{array}$ \\
\hline Termination by combination & $\mathrm{P}_{\mathrm{i}}+\mathrm{P}_{\mathrm{m}} \stackrel{\mathrm{k}_{8}}{\longrightarrow} \mathrm{L}_{\mathrm{i}+\mathrm{m}}$ & $\mathrm{k}_{8}=4.074 \times 10^{-1} \mathrm{~L} \mathrm{~mol}^{-1} \mathrm{~s}^{-1}$ & $\begin{array}{c}\text { Zhang and Ray } \\
\text { (2002) }\end{array}$ \\
\hline
\end{tabular}
component. The $\mathrm{L}_{\mathrm{i}, \mathrm{j}}$ represents the dead chains.

Table 4: Kinetic Constants And Possible Reactions During The Polymerization 1 
Table 3: Kinetic constants and possible reactions during the polymerization 2.

\begin{tabular}{|c|c|c|c|}
\hline Step & Mechanism & Expressions for kinetic constants & References \\
\hline \multirow{5}{*}{ Initiation } & $\mathrm{I} 1 \stackrel{\mathrm{k}_{1}}{\longrightarrow} 2 \mathrm{R} 1$ & $\mathrm{k}_{1}=8.775 \times 10^{-3} \mathrm{~s}^{-1}$ & $\begin{array}{l}\text { Zhang and Ray } \\
\text { (2002) }\end{array}$ \\
\hline & $\mathrm{I} 2 \stackrel{\mathrm{k}_{2}}{\longrightarrow} 2 \mathrm{R} 2$ & $\mathrm{k}_{2}=7.593 \times 10^{-4} \mathrm{~s}^{-1}$ & $\begin{array}{l}\text { Dhib, Gao and } \\
\text { Penlidis (2000) }\end{array}$ \\
\hline & $\mathrm{R} 1+\mathrm{M}_{1} \stackrel{\mathrm{k}_{3}}{\longrightarrow} \mathrm{P}_{1,0}$ & $\mathrm{k}_{3}=4.340 \times 10^{-2} \mathrm{~L} \mathrm{~mol}^{-1} \mathrm{~s}^{-1}$ & $\begin{array}{l}\text { Zhang and Ray } \\
\text { (2002) }\end{array}$ \\
\hline & $\mathrm{R} 2+\mathrm{M}_{1} \stackrel{\mathrm{k}_{4}}{\longrightarrow} \mathrm{P}_{1,0}$ & $\mathrm{k}_{4}=1.367 \times 10^{-3} \mathrm{~L} \mathrm{~mol}^{-1} \mathrm{~s}^{-1}$ & $\begin{array}{l}\text { Dhib, Gao and } \\
\text { Penlidis }(2000)\end{array}$ \\
\hline & $\mathrm{R} 2+\mathrm{M}_{2} \stackrel{\mathrm{k}_{5}}{\longrightarrow} \mathrm{Q}_{0,1}$ & $\mathrm{k}_{5}=1.367 \times 10^{-3} \mathrm{~L} \mathrm{~mol}^{-1} \mathrm{~s}^{-1}$ & $\begin{array}{l}\text { Dhib, Gao and } \\
\text { Penlidis (2000) }\end{array}$ \\
\hline \multirow{4}{*}{ Propagation } & $\mathrm{P}_{\mathrm{i}, \mathrm{j}}+\mathrm{M}_{1} \stackrel{\mathrm{k}_{6}}{\longrightarrow} \mathrm{P}_{\mathrm{i}+1, \mathrm{j}}$ & $\mathrm{k}_{6}=4.340 \times 10^{-2} \mathrm{~L} \mathrm{~mol}^{-1} \mathrm{~s}^{-1}$ & $\begin{array}{l}\text { Zhang and Ray } \\
\text { (2002) }\end{array}$ \\
\hline & $\mathrm{P}_{\mathrm{i}, \mathrm{j}}+\mathrm{M}_{2} \stackrel{\mathrm{k}_{7}}{\longrightarrow} \mathrm{Q}_{\mathrm{i}, \mathrm{j}+1}$ & $\mathrm{k}_{7}=7.230 \times 10^{-2} \mathrm{~L} \mathrm{~mol}^{-1} \mathrm{~s}^{-1}$ & $\begin{array}{l}\text { Hutchinson and } \\
\text { Penlidis (2007) }\end{array}$ \\
\hline & $\mathrm{Q}_{\mathrm{i}, \mathrm{j}}+\mathrm{M}_{1} \stackrel{\mathrm{k}_{8}}{\longrightarrow} \mathrm{P}_{\mathrm{i}+1, \mathrm{j}}$ & $\mathrm{k}_{8}=1.165 \times 10^{-1} \mathrm{Lmol}^{-1} \mathrm{~s}^{-1}$ & $\begin{array}{l}\text { Hutchinson and } \\
\text { Penlidis (2007) }\end{array}$ \\
\hline & $\mathrm{Q}_{\mathrm{i}, \mathrm{j}}+\mathrm{M}_{2} \stackrel{\mathrm{k}_{9}}{\longrightarrow} \mathrm{Q}_{\mathrm{i}, \mathrm{j}+1}$ & $\mathrm{k}_{9}=4.660 \times 10^{-2} \mathrm{~L} \mathrm{~mol}^{-1} \mathrm{~s}^{-1}$ & $\begin{array}{c}\text { Wang and } \\
\text { Broadbelt (2009) }\end{array}$ \\
\hline \multirow{4}{*}{$\begin{array}{l}\text { Equilibrium with } \\
\text { nitroxide }\end{array}$} & $\mathrm{P}_{\mathrm{i}, \mathrm{j}}+\mathrm{X} \stackrel{\mathrm{k}_{10}}{\longrightarrow} \mathrm{Z}_{\mathrm{i}, \mathrm{j}}$ & $\mathrm{k}_{10}=3.799 \times 10^{1} \mathrm{~L} \mathrm{~mol}^{-1} \mathrm{~s}^{-1}$ & $\begin{array}{l}\text { Zhang and Ray } \\
\text { (2002) }\end{array}$ \\
\hline & $\mathrm{P}_{\mathrm{i}, \mathrm{j}}+\mathrm{X} \stackrel{\mathrm{k}_{11}}{\longleftarrow} \mathrm{Z}_{\mathrm{i}, \mathrm{j}}$ & $\mathrm{k}_{11}=2.500 \times 10^{-3} \mathrm{~s}^{-1}$ & $\begin{array}{l}\text { Zhang and Ray } \\
\text { (2002) }\end{array}$ \\
\hline & $\mathrm{Q}_{\mathrm{i}, \mathrm{j}}+\mathrm{X} \stackrel{\mathrm{k}_{12}}{\longrightarrow} \mathrm{W}_{\mathrm{i}, \mathrm{j}}$ & $\mathrm{k}_{12}=3.799 \times 10^{0} \mathrm{~L} \mathrm{~mol}^{-1} \mathrm{~s}^{-1}$ & $\begin{array}{l}\text { Zhang and Ray } \\
\text { (2002) }\end{array}$ \\
\hline & $\mathrm{Q}_{\mathrm{i}, \mathrm{j}}+\mathrm{X} \stackrel{\mathrm{k}_{13}}{\longleftarrow} \mathrm{W}_{\mathrm{i}, \mathrm{j}}$ & $\mathrm{k}_{13}=2.500 \times 10^{-2} \mathrm{~s}^{-1}$ & $\begin{array}{l}\text { Zhang and Ray } \\
\text { (2002) }\end{array}$ \\
\hline \multirow{3}{*}{$\begin{array}{l}\text { Termination by } \\
\text { combination }\end{array}$} & $\mathrm{P}_{\mathrm{i}, \mathrm{j}}+\mathrm{P}_{\mathrm{m}, \mathrm{n}} \stackrel{\mathrm{k}_{14}}{\longrightarrow} \mathrm{L}_{\mathrm{i}+\mathrm{m}, \mathrm{j}+\mathrm{n}}$ & $\mathrm{k}_{14}=4.074 \times 10^{-1} \mathrm{~L} \mathrm{~mol}^{-1} \mathrm{~s}^{-1}$ & $\begin{array}{l}\text { Zhang and Ray } \\
\text { (2002) }\end{array}$ \\
\hline & $\mathrm{Q}_{\mathrm{i}, \mathrm{j}}+\mathrm{Q}_{\mathrm{m}, \mathrm{n}} \stackrel{\mathrm{k}_{15}}{\longrightarrow} \mathrm{L}_{\mathrm{i}+\mathrm{m}, \mathrm{j}+\mathrm{n}}$ & $\mathrm{k}_{15}=4.697 \times 10^{-1} \mathrm{~L} \mathrm{~mol}^{-1} \mathrm{~s}^{-1}$ & $\begin{array}{c}\text { Wang and } \\
\text { Broadbelt (2009) }\end{array}$ \\
\hline & $\mathrm{P}_{\mathrm{i}, \mathrm{j}}+\mathrm{Q}_{\mathrm{m}, \mathrm{n}} \stackrel{\mathrm{k}_{16}}{\longrightarrow} \mathrm{L}_{\mathrm{i}+\mathrm{m}, \mathrm{j}+\mathrm{n}}$ & $\mathrm{k}_{16}=4.374 \times 10^{-1} \mathrm{~L} \mathrm{~mol}^{-1} \mathrm{~s}^{-1}$ & $\begin{array}{l}\text { Hutchinson and } \\
\text { Penlidis (2007) }\end{array}$ \\
\hline \multicolumn{2}{|c|}{$\begin{array}{l}\text { It is possible to notice that the adopted kinect model } \\
\text { uses the terminal hypothesis, to consider that the one } \\
\text { repeating unit that influences the reactivity of a given chain } \\
\text { in the terminal (Hutchinson and Penlidis, 2007), therefore, } \\
\text { the chain size and the repeating units sequence do not } \\
\text { influence in the reactivity rate. } \\
\text { In the Polymerization 2, during the simulations, it } \\
\text { was noted that after the homopolymerization in the first } \\
\text { stage of the reactor, all BPO and associated radical to this } \\
\text { initiator were consumed, therefore, this compound is not } \\
\text { present when the lateral feed go in. Hence, the reaction of } \\
\text { the radical from BPO and MMA monomers is not possible, } \\
\text { because this monomer is inserted only by later currents. } \\
\text { Thus, this reaction was not accounted for in Table } 5 \text {. }\end{array}$} & \multicolumn{2}{|c|}{$\begin{array}{l}\text { given the initiator quantity used, in simulated samples with } \\
1,000 \text { produced chains. This volume was partitioned in } n= \\
10 \text { equal fractions and each one was simulated by defined } \\
\text { time by RTD. } \\
\text { For the modeling of Araújo and Pinto (2013) study, it } \\
\text { is assumed that the tubular reactor RTD is represented by a } \\
\text { log-normal function. This distribution was characterized by } \\
\text { the residence times exhibited in Table } 2 \text { and for calculated } \\
\text { variances through typical values for polymerization in a } \\
\text { tubular reactor (Lemos, Melo and Pinto, 2015). The } \\
\text { associated variances to the respective residence times are } \\
\text { presented in Table } 6 \text {. } \\
\text { Table } 4 \text { : Variance and respective residence times of RTD } \\
\text { (Araujo and Pinto, 2013). }\end{array}$} \\
\hline \multirow{5}{*}{\multicolumn{2}{|c|}{$\begin{array}{l}\text { The nitroxide/initiator rate used was } 1.25 \text {, from } \\
\text { which it is possible to calculate the number of moleculas of } \\
\text { each reagent when applied to the magnitude of Table } 1 \text {. The } \\
\text { adopted sample volume, compatible with the values } \\
\text { practiced in the literature (Al-Harthi et al. } 2009 \text {; Wang and } \\
\text { Broadbelt, 2009; Van Steenberge et al., 2012; Lemos, Melo } \\
\text { and Pinto, 2015), it was } \mathrm{V}=10^{-17} \mathrm{~L} \text {, value that results, }\end{array}$}} & Residence Time (s) & Variance $\left(s^{2}\right)$ \\
\hline & & 4380 & $4.63 \times 10^{6}$ \\
\hline & & 4920 & $5.84 \times 10^{6}$ \\
\hline & & 1340 & $4.16 \times 10^{7}$ \\
\hline & & 19680 & $9.34 \times 10^{7}$ \\
\hline
\end{tabular}


Polymerization 1 was simulated on an identical form of the previous subsection, through a unique process in a tubular reactor. However, to simulate the different sections in the Araújo and Pinto (2013) reactor in the Polymerization 2 , it was modeled two tubular reactors configured in series. Therefore, the styrene homopolymerization stage is accomplished in the first reactor and the copolymerization in the second, being the latter fed with the first product and a secondary current having MMA and TEMPO.

The algorithm to accomplish these simulations were described in $\mathrm{C}++$ language, through the Dev $\mathrm{C}++$ software, the choice that was made according to the great processing velocity and dynamic allocation of data, an important characteristic for the implementation of computationally intensive processes, as the Monte Carlo simulations.

\section{RESULTS AND DISCUSSION}

\subsection{Polymerization 1 - Styrene Homopolymerization}

The four simulations were performed through the utilization of described models and parameters. The Tables 7 and 8 synthesize the comparison between the simulation results of the present paper and the experimental data obtained by Araújo and Pinto (2013) for the Polymerization 1 , where there is the formation of homopolymer polystyrene, being the first for a residence time of 82 minutes and the second for 328 minutes. The presented error was calculated through Equation 8, where $X_{\text {sim }}$ and $X_{\text {exp }}$ represent the simulated and experimental values, respectively.

$$
\operatorname{Error}(\%)=\frac{\left(X_{\text {exp }}-X_{\text {sim }}\right)}{X_{\text {exp }}}(100 \%)
$$

Table 5: Comparative results for Polymerization 1 system for the average residence time of 82 minutes condition.

\begin{tabular}{lccc} 
& $\begin{array}{c}\text { Experimental } \\
\text { (Araujo and } \\
\text { Pinto, 2013) }\end{array}$ & $\begin{array}{c}\text { Simulation } \\
\text { [present paper] }\end{array}$ & $\begin{array}{c}\text { Error } \\
\text { (\%) }\end{array}$ \\
\hline $\begin{array}{l}\text { Conversion } \\
(\%)\end{array}$ & 32.5 & 32.7 & 0.61 \\
PDI & 1.39 & 1.38 & 0.72 \\
$\begin{array}{l}\text { Molar mass } \\
(\mathrm{g} / \mathrm{mol})\end{array}$ & 28461.54 & 21887.12 & -23.1 \\
\hline
\end{tabular}

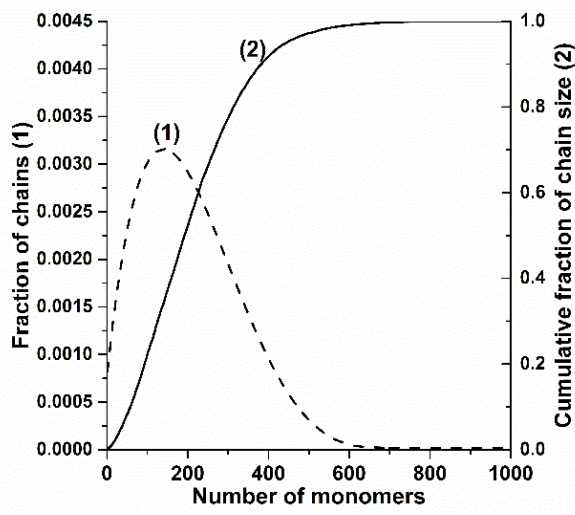

Table 6: Comparative results for Polymerization 1 system for the average residence time of $\mathbf{3 2 8}$ minutes condition.

\begin{tabular}{lccc} 
& $\begin{array}{c}\text { Experimental } \\
\text { (Araujo and } \\
\text { Pinto, 2013) }\end{array}$ & $\begin{array}{c}\text { Simulation } \\
\text { [present paper] }\end{array}$ & $\begin{array}{c}\text { Error } \\
(\%)\end{array}$ \\
\hline $\begin{array}{l}\text { Conversion } \\
(\%)\end{array}$ & 65.0 & 50.8 & -21.85 \\
PDI & 1.38 & 1.36 & -1.45 \\
$\begin{array}{l}\text { Molar mass } \\
(\mathrm{g} / \mathrm{mol})\end{array}$ & 40000 & 35671.37 & -10.82 \\
\hline
\end{tabular}

It is possible to note the simulation efficiency to estimate the PDI of the involved chains in the reaction, presenting results close to the experimental. This finding leads to the belief that the kinetic model is suitable to find how the chain sizes are distributed in the product. Regarding the molecular molar mass and the conversion, the results might be classified as reasonable and it illustrates that the kinect model used may need improvement.

It is noticed a decline in the error referent to the molecular molar mass estimative through the increase of the residence time. Besides the kinect model, possible discrepancies might resulted from the isothermality hypothesis, because experimental does not have validity in big extension, given the conducted reaction is highly exothermic (Billmeyer, 1984). The temperature increase tends to raise the kinetic constants and to accelerate the reactions. Positives deviations for the conversion might be explained for the disregard of the chain transference stage in the simulation (Wang and Broadbelt, 2009). As it is in the Araújo and Pinto (2013) article, there is an increase in the chains average molar mass with the increment of the residence time, which indicates success in the establishment of living/controlled character of the reaction. Unlikely the authors (Araujo and Pinto, 2013), as this paper considers only two experimental conditions, it can not be affirmed that there is a high linear correlation between the residence time and the chain size, as the theory indicates to occur in CRP, but it is reinforced the indicative that the microstructure control was well established.

Figure 1 exhibits the chain size distributions on a numeric basis for the polymeric samples obtained by simulations of two scenarios of residence time. The distributions non-accumulated were obtained through the derivation of the accumulated distributions.

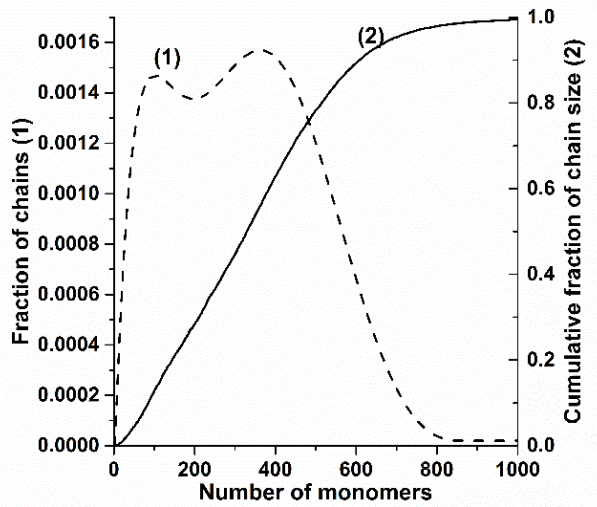

Figure 1 - Molar CLD for the residence time of 82 (left) and 328 minutes (right). The non-accumulated distributions are presented by dashed lines and the accumulated distributions, by filled lines. 
It is noticeable, as the CLD is sensitive to the residence times distribution, that the reactor presents, because it assumes the lognormal distribution form of the reactor, in a coherent form with the previous results (Lemos, Melo and Pinto, 2015). It is also perceptible a bigger dispersion on the size when the greater the residence time, as shown in Table 6. It is noticed how the distribution dislocated for the right with the increase of the residence time, given the living/controlled character of the polymerization.

The CLD for the residence time of 328 minutes is bimodal, as shown in Figure 1. A possible explanation for this behavior would be the living/controlled character of the reaction, which could suffer an elevate terminations number, initially, due to the low rate between the capture agent and the initiators quantities, less than 2, what is the minimum rate for all the living chains to be transformed in dormant (Meyer and Keurentjes, 2005). The verification of this hypothesis is exhibited in Figure 2, which presents the medium chain number variation within the time for a partition of the simulated volume.

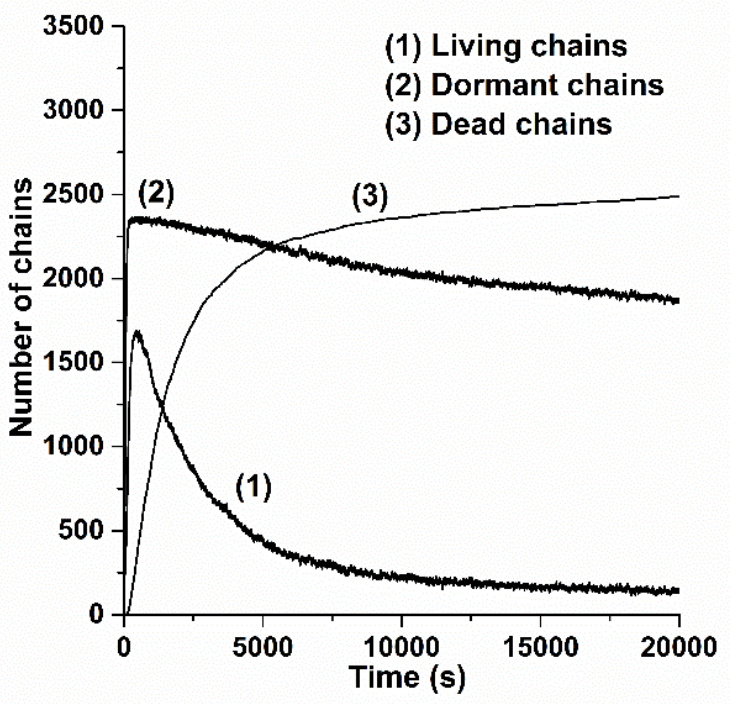

The comparison between the two presented images in Figure 2, demonstrated that the use of a bigger nitroxide/initiator rate leads to a small initial peak in the living and dead chains. The nitroxide depletion is almost instant in the two cases, showing a high spontaneity in the capture reaction. Although, over time, it is noticed the targeting for a stage in which the living chains and terminations number are low, besides the decapture become more probable than the capture, due to the elevate dormant chains number.

The high terminations number at the beginning of the process leads to the formation of the first mode in the bimodal graphic, in Figure 1, given the chains cannot achieve a reasonable size. The peak is due to the living/dormant chains, that might suffer propagation in future times and, consequently, reaching great sizes. Figure 3 exhibits this information, through the chain size distribution of the living/controlled and dormant structures.

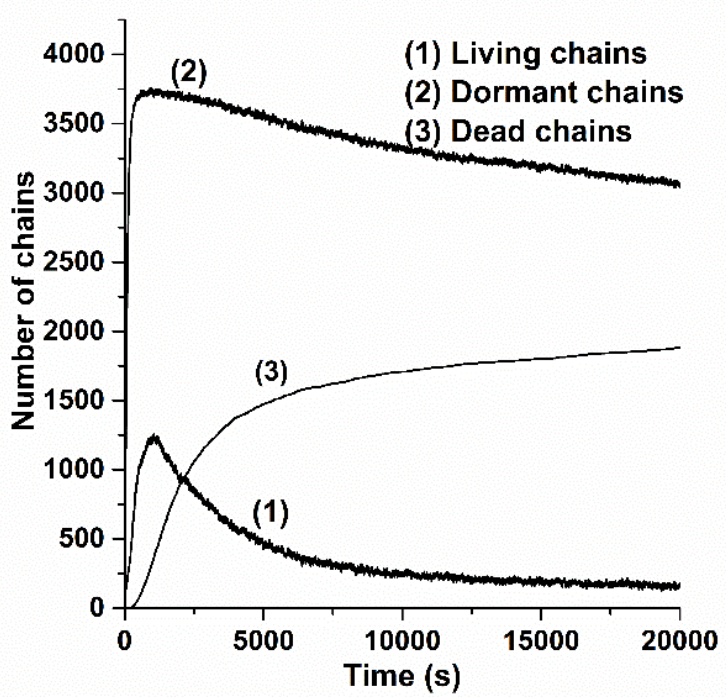

Figure 2 - Chains number variation within the time for the residence time of $\mathbf{3 2 8}$ minutes. Nitroxide/initiator rate equals to 1.25 (left) and 2.00 (right).
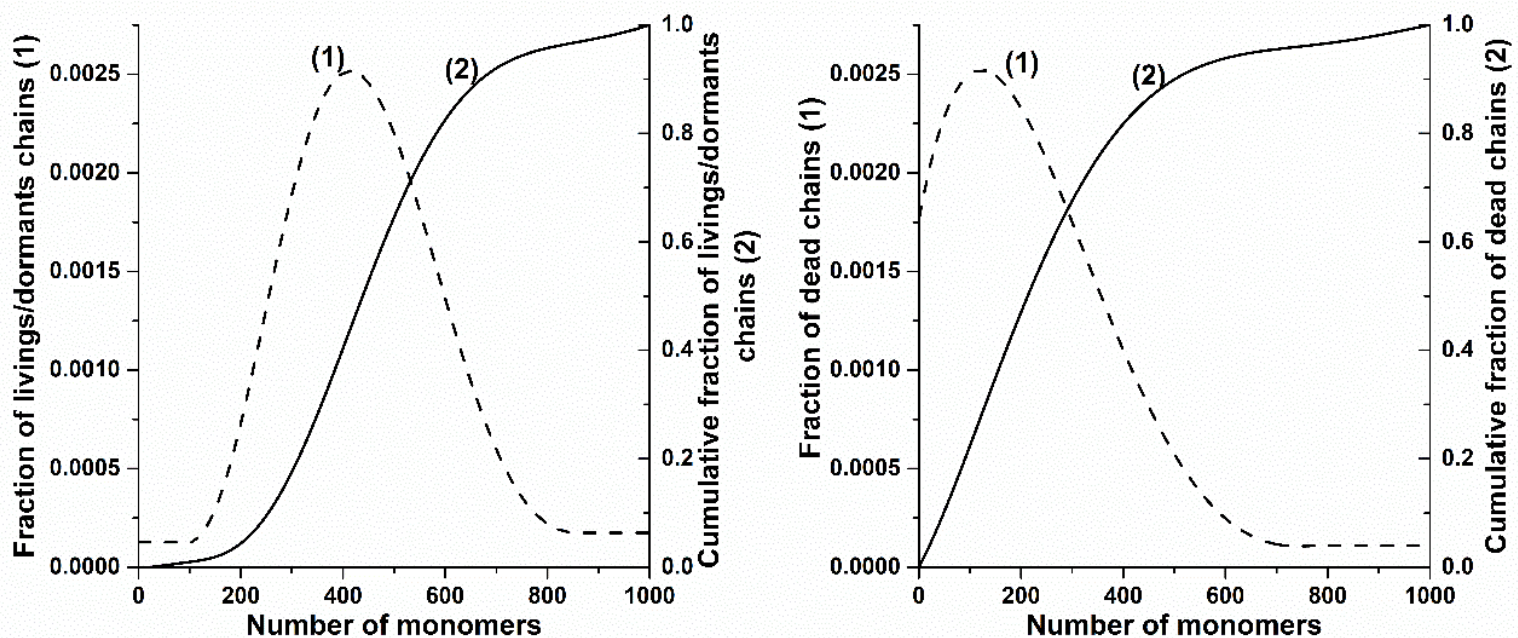

Figure 3 - Molar CLD for the residence time of 328 minutes, living/dormant (left) and deads (right) chains. 
In Figure 3, it is explicit the central behavior of the living/dormant chains distributions, while the dead chains present strong displacement for the left. To complement the graphic information of Figure 3, it was measured by the algorithm of the average chain size. Being accounted for sizes of 434.89 and 265.21 monomers per chain for the living/dormant and dead chains, respectively. The graphic from the left in Figure 1 does not present bimodality due to small permanence time in the reactor, which does not allow the chain propagation to create a second peak.

\subsection{Polymerization 2 - Styrene-MMA Copolymerization}

The Polymerization 2 treats the system that has lateral feed to the tubular reactor, the one that Araújo and Pinto (2013) attribute the possible formation of tapered block copolymers based on styrene and MMA. Table 9 exhibits a comparison between the experimental and obtained through simulation results for the average residence time of 155 minutes.

Table 9 - Comparative results for the Polymerization 2 system for the average residence time of 155 minutes.

\begin{tabular}{lccc} 
& $\begin{array}{l}\text { Experimental } \\
\text { (Araujo and } \\
\text { Pinto, 2013) }\end{array}$ & Simulated & $\begin{array}{l}\text { Error } \\
(\%)\end{array}$ \\
\hline $\begin{array}{l}\text { Global } \\
\text { Conversion } \\
(\%)\end{array}$ & $54.29 \%$ & $42.60 \%$ & $-21.53 \%$ \\
$\begin{array}{l}\text { Styrene } \\
\text { Conversion } \\
(\%)\end{array}$ & - & $45.60 \%$ & - \\
$\begin{array}{l}\text { MMA } \\
\text { conversion (\%) }\end{array}$ & - & $17.20 \%$ & - \\
$\begin{array}{l}\text { PDI } \\
\text { Molar mass } \\
\text { (g/mol) }\end{array}$ & 1.33 & 1.35 & $1.50 \%$ \\
\hline
\end{tabular}

Based on Table 9, it is again observed that the adopted kinect model is optimum to predict the PDI, being reasonable in the conversion and molar mass prediction. It is opportune to say the kinect model was built by kinect data compilation at different sources. These data were certainly estimated using distinct reaction conditions and raw materials, to turn the differences understandable. The average styrene composition obtained via simulation was $95.50 \%$, then, the MMA incorporation was low.

Figure 4 presents the molar CLD of the created chain size, for the scenario with the average residence time of 155 minutes.

Relevant information for the microstructure knowledge as the produced copolymer is the size of the first styrene block formed in the tubular section that precedes the lateral feed. The average size found for this first block was 195.23 repeating units, while the average styrene size and MMA of the others were 4.50 and 1.06 repeating units, respectively. Figure 5 exhibits the block length distribution for each component, it can be noticed a greater tendency to styrene incorporation, while the MMA is inserted and substituted.

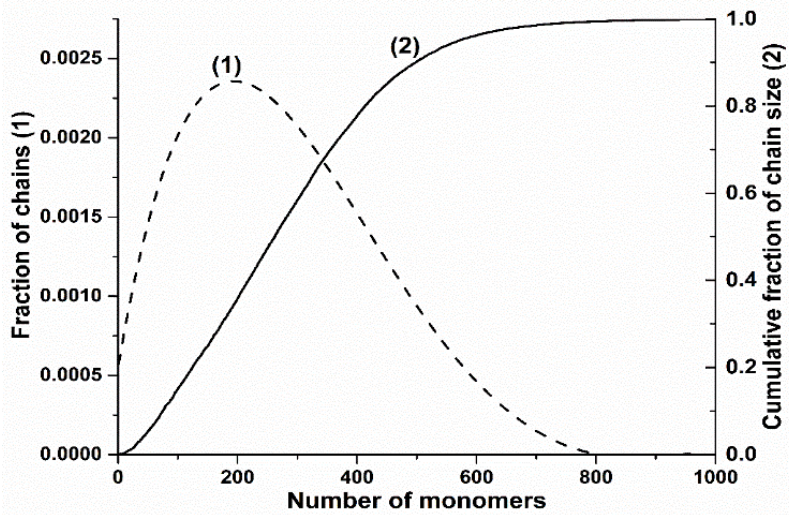

Figure 3: Molar CLD for the residence time of 155 minutes. The non-accumulated distributions are represented by dashed lines and the accumulated distributions by filled lines.

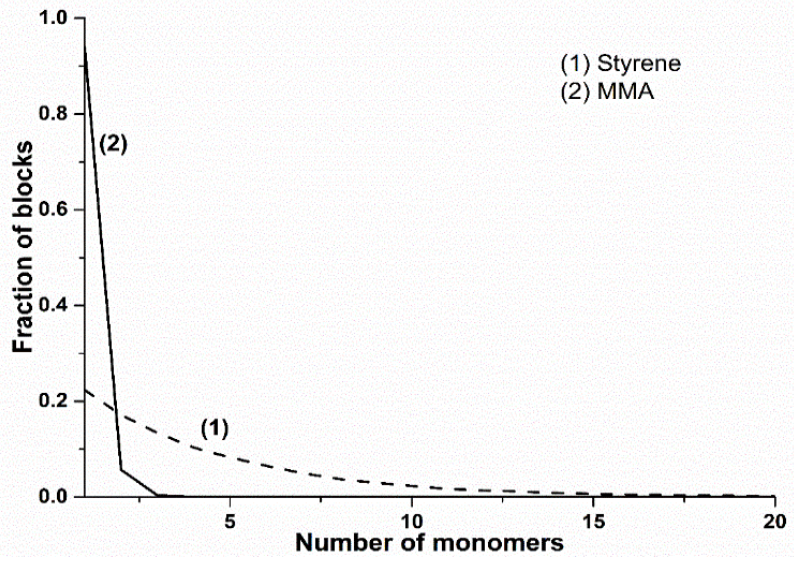

Figure 4: The distribution function for the number of monomers per block for each type of forming monomer, residence time of $\mathbf{1 5 5}$ minutes.

Figure 5 complements the information that the MMA forms blocks smaller than the styrene, a fact due to the great difference in the concentration between the two species, which tends to favor a higher styrene propagation, given the kinetic constants of the propagation reaction of the two molecules are very similar, as presented in Table 5. It is also inferred that the styrene composition drift does not occur so the local MMA incorporation increases, forming a gradient. Therefore, the copolymers generated in the simulation are the polystyrene- $b$-poly(methyl styrene-rand-methacrylate) or polystyrene- $b$-poly(methyl styrene-alt-methacrylate), not having the formation of polystyrene- $b$-poly(methyl styrenegrand-methacrylate), as suggested by the authors (Araujo and Pinto, 2013). 
Figure 6 presents the image that illustrates the microstructure of the created polymers. The microstructure image was developed through the production of a data matrix which represents the polymeric chains mer unit to mer unit for different numbers so that an image was produced after the attribution of color contrast for each number, a fact also found in other papers (Van Steenberge et al., 2012; Lemos, Melo and Pinto, 2015). On the image, the gray tone represents the styrene, the white tone the MMA and the background is black.

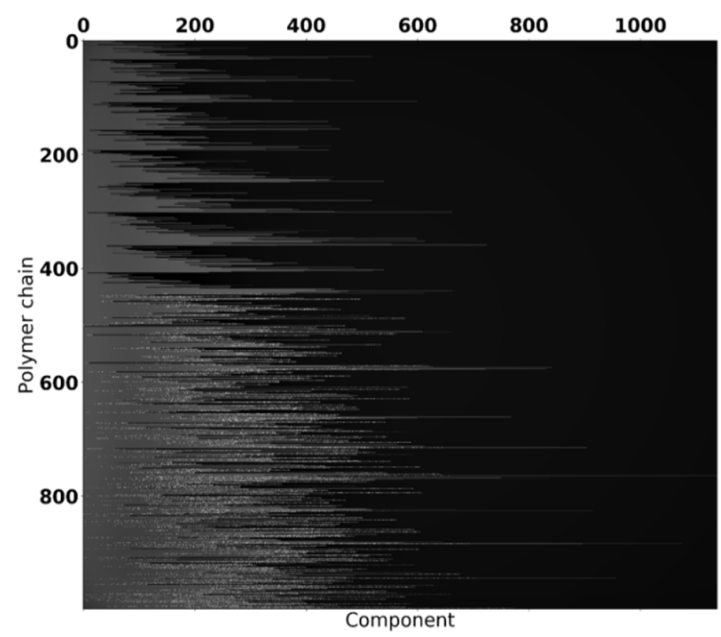

Figure 5: Microstructural image of the polymeric chains formed for the residence time of $\mathbf{1 5 5}$ minutes.

Figure 6 exhibits that nearly half the represented chains are homopolymers, this is due to the first stage of the process is a homopolymerization, which a great number of chains suffer termination. As discussed previously, in the explication of the bimodality present in Figure 1, one of the reasons would be the nitroxide/initiator low proportion used, besides its division between the principal and lateral currents.

The Araújo and Pinto (2013) study also conducted the Polymerization type 2 for a residence time of 547 minutes. The comparisons of the obtained results via simulation and experimentally are expressed in Table 10.

Table 10 - Comparative results for the Polymerization 2 system for the average residence time of 547 minutes

\begin{tabular}{lccc} 
& $\begin{array}{c}\text { Experimental } \\
\text { (Araujo and } \\
\text { Pinto, 2013) }\end{array}$ & $\begin{array}{c}\text { Simulated } \\
\text { [present } \\
\text { paper] }\end{array}$ & $\begin{array}{c}\text { Error } \\
\text { (\%) }\end{array}$ \\
\hline $\begin{array}{l}\text { Conversion } \\
(\%)\end{array}$ & $60.00 \%$ & $51.45 \%$ & - \\
$\begin{array}{l}\text { Styrene } \\
\text { conversion } \\
(\%)\end{array}$ & - & $55.29 \%$ & - \\
$\begin{array}{l}\text { MMA } \\
\text { conversion } \\
(\%)\end{array}$ & - & $14.25 \%$ \\
PDI & 1.40 & 1.42 & $1.43 \%$ \\
$\begin{array}{l}\text { Molar mass } \\
(\mathrm{g} / \mathrm{mol})\end{array}$ & 42000.00 & 42741.97 & $1.77 \%$ \\
\hline
\end{tabular}

For this situation, the used models managed to predict the PDI and the molar mass in a precise form. The algorithm presented that over the created chains, there were $96.04 \%$ styrene mer units. A microstructure image of the formed chains is presented in Figure 7.

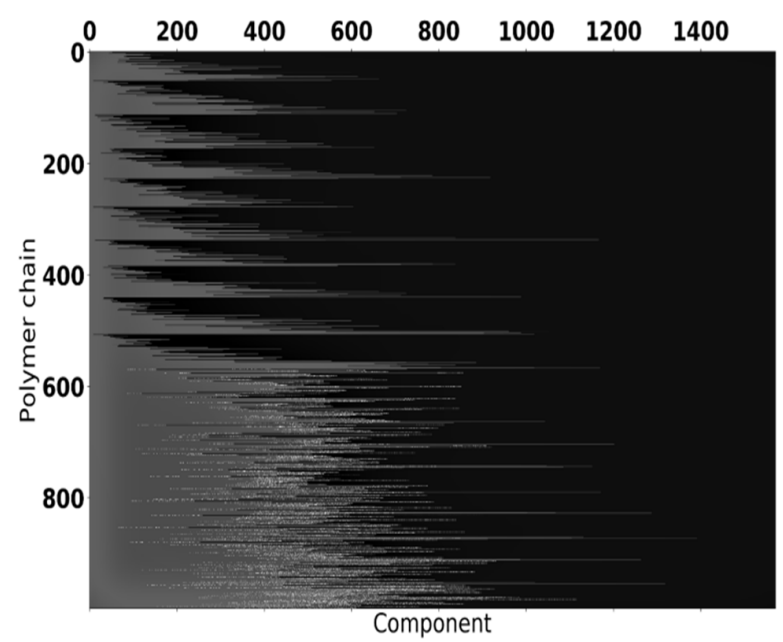

Figure 7 - Microstructural image of the polymeric chains formed for the residence time of 547 minutes.

In Figure 7, there are the same aspects that Figure 6, therefore, there is not the formation of a chain section with a composition gradient. To obtain the gradient, it is recommended the utilization of another recipe, with greater quantities of MMA and lower quantities of styrene, including in the main reactor feed. The low presence of MMA in the chains is due to the majority styrene presence in the reactional medium, besides the substitution reaction of the MMA by styrene in the propagation stage is of a superior magnitude to the three others reactions, as it is exhibited in Table 5 .

Figure 8 presents the distributions function for the chain sizes on a molar basis and the block length distribution for both components for the system.

About the same distributions only for the residence time of 155 minutes, the distributions of Figure 8 presented a displacement for the right, besides a stronger bimodal aspect, as predicted by Araújo and Pinto (2013). The average size of the first styrene block was 331.51 repeating units, while the average size for the others styrene and MMA blocks was 3.64 and 1.09 repeating unit, respectively. Comparatively, the behavior of these graphics did not suffer great alteration with residence time increase, having a small decrease in the styrene length blocks. This is due to the excessive consumption of the compound for a long time, leading to more effective incorporation of MMA monomers. 

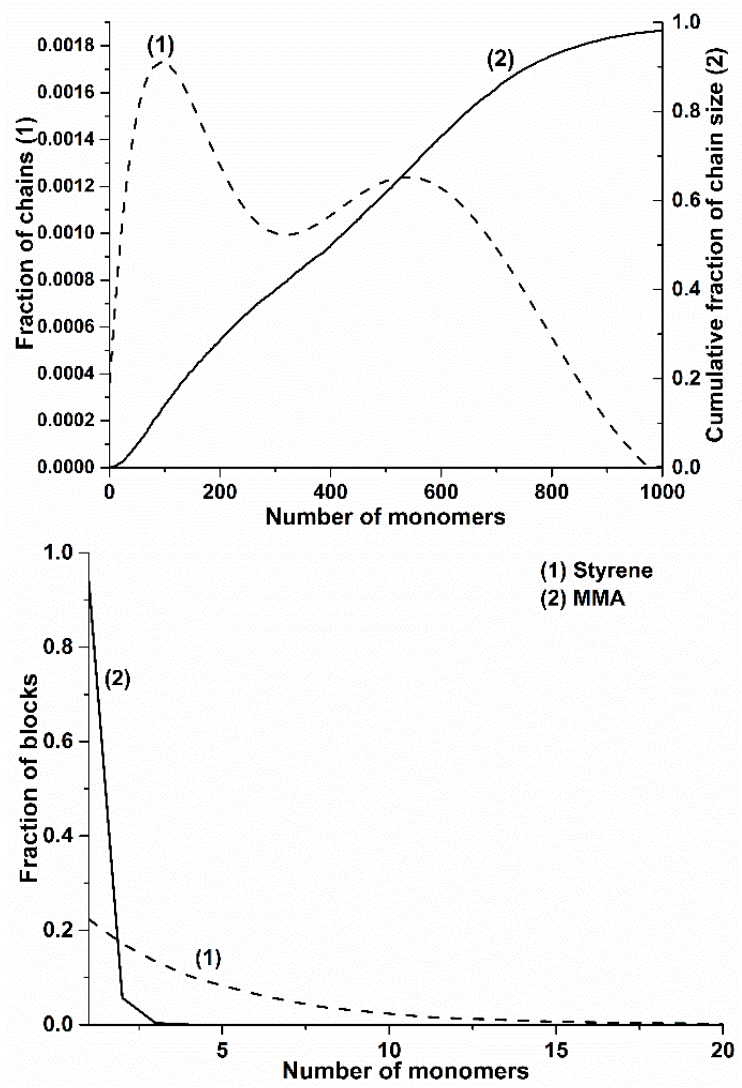

Figure 8 - Chain (left) and block length distributions for each monomer species (right) for the residence time of 547 minutes.

\section{CONCLUSION}

This paper modeled the production process of copolymers with living/controlled microstructures in a continuous reactor. NMP was used to produce copolymers based on styrene and methyl methacrylate in a tubular reactor with a lateral feed. This configuration proposition turns possible to produce polymeric materials of innovative microstructure that might present processing properties and original applications.

For described polymerization in Araújo and Pinto (2013) paper, there were simulated by $\mathrm{kMC}$, using the Lemos et al. (2015) methodology. The kinect model and the used hypothesis presented to be successful for the PDI prediction in created polymeric chains, however, it was not reliable in the determination of the conversion and molar masses. The characterization of the formed product was complete, therefore, it was defined all necessaries Distributions Functions, besides the presentation of the obtained microstructure.

It was verified, for the used conditions, the formed product differed from the desired in the experiments. There were found copolymers of polystyrene- $b$-poly(methyl styrene-rand-methacrylate) or polystyrene- $b$-poly(methyl styrene-alt-methacrylate), not being found any regions that presented the composition gradient over the chains, a result that shows the relevance in the stochastic simulations in the decision making process in the engineering context of polymerization reactions.

\section{REFERENCES}

AL-HARTHI, M.; KHAN, M. J.; ABBASI, S. H.; SOARES,

J. B. P. Macromolecules Reaction Engineering. 3, 148 (2009).

ARAÚJO, C. L.; PINTO, J. C. Macromolecules Symposium. 333, 62 (2013).

BEERS, K. L.; GRAYNOR, S. G.; MATYJASZEWSKI, $\mathrm{K}$;

SHEIKO, S. S.; MOELLER, M. Macromolecules. 31, 9413 (1998).

BENDEJACQ, D.; PONSINET, V.; JOANICOT, M.; LOO, Y. L.; REGISTER, R. A. Macromolecules. 35, 6645 (2002).

BILLMEYER JR., F. W. Textbook of Polymer Science (Wiley-Interscience, New York, 1984).

BRANDÃO, A. L. T.; SOARES, J. B. P.; PINTO, J. C.; ALNERTPM, A. L. Macromolecules Reaction Engineering. 9, 141 (2015).

DHIB, R.; GAO, J.; PENLIDIS, A. Polymer Reaction Engineering. 8, 299 (2000).

GILLESPIE, D. T. Journal of Computational Physics. 22,403 (1976).

HILLMYER, M. A. Journal of Polymer Science Part B: Polymer Physics. 45, 3249 (2007).

HUSTAD, P. O.; KUHLMAN, R. L.; ARRIOLA, D. J.;CARNAHAN, E. M.; WENZEL, T. T. Macromolecules. 40, 7061 (2007).

HUTCHINSON, R. A.; PENLIDIS, A. Polymer Reaction Engineering. 118 (2007).

LEMOS, T.; MELO, P. A.; PINTO, J. C. Macromolecules Reaction Engineering. 9, 259 (2015).

MEYER, T.; KEURENTJES, J. Z, Handbook of Polymer Reaction Engineering (Wiley-VCH, Weinheim)

MORSBACH, J.; MULLER, A. H. E.; BERGENNICOLLETTI, E.; FREY, H. Macromolecules. 49, 5043 (2016).

ODIAN, G. Principles of Polymerization (WileyInterscience, New York, 2004).

RUBINSTEIN M.; COLBY R. H. Polymer Physics (Oxford, Pennsylvania, 2003).

TOBITA, H. Macromolecules. 26, 836 (1993).

TREPKA, W. J. US Patent No. 5130377 (1992).

VAN STEENBERGE, P. H. M.; D'HOOGE, D. R.; WANG, Y.; ZHONG, M.; REYNIERS, M.; KONKOLEWICZ， D.; MATYJASZEWSKI， K.; MARIN, G. B. Macromolecules. 45, 8519 (2012).

WANG, L.; BROADBELT L. J. Macromolecules. 42, 7961 (2009).

ZHANG, M.; RAY, W. H. Journal of Applied Polymer Science. 86, 1630 (2002). 